\title{
Mass Transfer over a Film-Cooled Turbine Blade
}

\author{
PING-HEI CHEN and JR-MING MIAO \\ Department of Mechanical Engineering, National Taiwan University, Taipei 10764, Taiwan, R.O.C.
}

\begin{abstract}
A naphthalene sublimation technique was employed to study the mass transfer distributions over a turbine blade surface with secondary flows ejected in the spanwise direction through three rows of equally-spaced injection holes located in the leading edge region. The mass transfer measurements were conducted in a range of blowing ratios from 0.6 to 1.2 at two different mainstream turbulence levels $(0.4 \%$ and $6.0 \%)$ while keeping the exit Reynolds number, $R e_{2}$, at a constant value of 397,000 .
\end{abstract}

Key Words: turbine blade, film cooling, turbulence level, mass transfer

T The measured results are presented to illustrate the effects of the blowing ratio and the approaching mainstream turbulence level on both local and spanwiseaveraged mass transfer distributions over the blade surface. The presence of secondary flows promotes the mass transfer rates over both surfaces of the test blade. As the secondary flows are ejected from the injection holes, a large and periodic variation in the spanwise mass transfer rate is observed in the region which extends from the location of injection hole to the central portion of the turbine blade surface for all runs. The mass transfer rates in the region near the injection holes increase with the blowing ratio except for those over the pressure surface at $T u=0.4 \%$ and $M=1.2$.

\section{INTRODUCTION}

Since the material of the gas turbine blade cannot sustain the high temperature of the exhausted gas flow from the combustion chamber, some cooling techniques are used to protect the turbine blade material. Shower-head film cooling is one of the widely employed and important cooling methods used to protect the external surface of the first stage rotor. Once the coolant flows are ejected through multiple-row of injection holes, the interaction between the secondary flows and the mainstream becomes very complicated, so does the convective transport phenomena associated with this complex flow field.

In order to improve the efficiency of the gas turbine engine, the temperature of the exhausted gas flow is progressively raised to the limit at which the current cooling method can still protect the gas turbine surface. Therefore, employment of the film cooling method requires a deeper understanding of the flow field and the heat transfer characteristics in order to better protect the turbine blade surface. As the secondary flows (ejected jets) are present, it is well known that the convective transport phenomena over the turbine blade is affected by many parameters such as: blade curvature, mainstream turbulence level, pressure gradient, unsteady passing wake, direction of the ejected flow, density ratio, and blowing ratio. However, the present investigation only focuses on the effects of the mainstream turbulence level and the blowing ratio on the mass transfer distributions over the film-cooled blade surface.

For years, numerous numerical and experimental studies have been conducted in order to provide valuable design data related to shower-head film cooling. Recent efforts have focused on the detailed local mass (or heat) transfer coefficient and film cooling effectiveness measurements in regions downstream or between the injection holes. In the prior studies, the coolant flows are ejected through single or multiple-row of injection holes located on a flat plate, a circular cylinder, or a scale-up turbine blade. Because many individual parameters have a strong effect on shower-head film cooling, there is still a lack of understanding about the convective transport phenomena over the blade surface under the influence of the interaction between the secondary flows and the mainstream. 
To study the film cooling phenomena over a flat plate, Goldstein and Taylor [1982] (employing the same naphthalene sublimation technique as the present study) investigated the mass transfer phenomena over a flat plate as secondary jets were ejected through a row of three inclined holes which have an injection angle of 35 degrees to the streamwise direction into a crossflow. Their measured results indicated that the presence of jets at high blowing ratios can be considered as the solid blockage to the mainstream. Demuren et al. [1986] predicted the film cooling effectiveness at different test cases by varying the hole spacing, the injection angle, and the blowing ratio in using a finite volume method. Their results showed that there still existed a significant discrepancy between both numerical and experimental results. Honami et al. [1994] conducted a surface temperature measurement on a flat surface where coolant flows were ejected at a $30^{\circ}$ angle to the spanwise direction through a row of injection holes. Temperature on the flat plate surface was measured by a liquid crystal technique in this study. Due to the interaction of the mainstream and the jets, an asymmetrically large vortex motion was observed on one side of the injection holes. Besides, due to the presence of vortex motion, the film cooling effectiveness is expected to be low. For multiplerow injections, Jubran and Brown [1985] conducted experimental measurements for investigating film cooling from two rows of holes in the streamwise and spanwise directions. A better film protection on the surface was obtained for two-row injection than one-row injection.

Tillamn et al. [1985] predicted the ejected cooling flow rates through circular holes on cylindrical models with and without inserts in the hollow section of cylinders. They reported that the pressure losses across the insert and the cooling holes could be calculated separately if an insert was installed in the cylinder model. The mass transfer distributions over a circular cylinder were reported by Karni and Goldstein [1990] and Chen et al. [1994a] by introducing the secondary flows through spanwisely or streamwisely oriented injection holes. Mick and Mayle [1988] measured both the heat transfer coefficient and the film cooling effectiveness distributions over a blunt body which was composed of a semicylinder leading edge and a flat afterbody. The heat transfer rate could be augmented by three times compared with those cases without injection holes while the secondary flows were being ejected.

Han and his co-workers (Mehendale et al., 1991; Mehendale and Han, 1992a; Ou, et al., 1992; Ou and Han, 1992 and 1994a) have conducted a series of studies by using the same model as that of Mick and Mayle
[1988] to investigate the effects of mainstream turbulence level and the blowing ratio on stagnation film cooling. If the secondary flows were ejected, their measured results illustrated that the heat transfer coefficient increased with the mainstream turbulence level only for cases at a blowing ratio of 0.8 ; but this trend was not observed for cases at other blowing ratios. A different correlation between the heat transfer coefficient and the blowing ratio was reported if the injection slots instead of the injection holes were utilized to simulate the stagnation film cooling. In addition, they also presented the influence of geometrical parameters of injection holes on the distributions of the heat transfer coefficient and film cooling effectiveness.

Instead of conducting the measurements on a simplified model, the film cooling performance was evaluated on a scale-up turbine blade by Ito et al. [1978], Dring et al. [1980], Taylor [1980], Sakata and Kumagai [1983], Chen and Goldstein [1992], Nirmalan and Hylton [1990], Camci and Arts [1985, 1990], Yamamoto et al. [1991], Takeishi et al. [1992], Abhari and Epstein [1994], Menhendale et al. [1994], and Ou and Han [1994b].

Despite the number of experiments conducted, none reported the detailed local mass or heat transfer distributions over the film cooled turbine blade surface under the effects of the mainstream turbulence level and the blowing ratio. The purpose of present paper is to conduct mass transfer measurements over a turbine blade with secondary flows through three rows of injection holes which are oriented at 30 degrees to the spanwise direction. High mainstream turbulence level was produced by installing a bar grid upstream of the turbine blade cascade and the blowing ratio was varied in a range of $M$ $=0.6$ to 1.2 .

\section{EXPERIMENTAL APPARATUS}

\section{Test Apparatus}

Figure 1 shows the schematic view of the test facility in which the mass transfer experiments were conducted. The test facility is composed of two main systems: a low-speed, open and blowing-type wind tunnel and a secondary flow system. The wind tunnel and the bar grid used for promoting mainstream turbulence level were also employed in the present study and the detailed descriptions can be found in Chen et al. [1994b]. In addition, the detailed geometrical data about the test planar cascade is referred to those in the paper of Chen et al. [1994b]. 


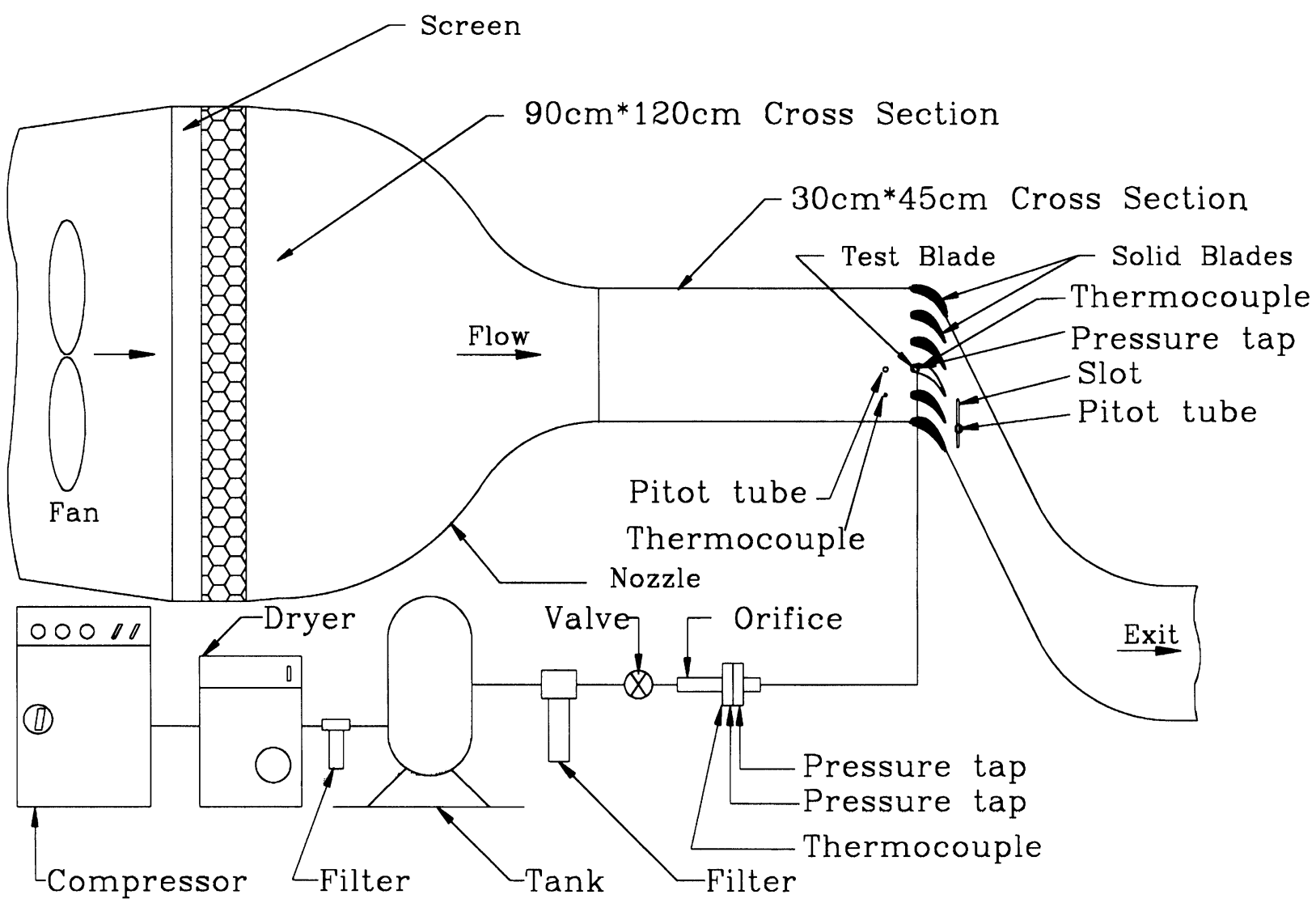

FIGURE 1 Schematic view of the test facility.

To provide the secondary flows through the injection holes of the test turbine blade, the secondary flow system consists of a screw-type compressor, a dryer with a condenser, a storage tank, two filters, a regulator, and an orifice. The screw-type compressor can provide an air flow rate of $1154 \mathrm{~m}^{3} / \mathrm{min}$. at a gauge pressure of $8 \mathrm{~kg} / \mathrm{m}^{2}$. To eliminate the humidity in the air flow, the air flow first passes through the low-temperature condenser where excessive water vapor is condensed and then the air flow is heated up to the ambient temperature by the dryer. Two filters that can filter out a droplet size larger than $6 \mu \mathrm{m}$ and $1 \mu \mathrm{m}$ respectively are installed to ensure the purity of secondary flows. The mass flow rate of secondary flows is controlled by the regulator and measured by the calibrated flange-type orifice.

Since the naphthalene sublimation technique is employed in the present study, mass transfer occurs between the naphthalene-coated blade surface and mainstream as the test blade is exposed in the mainstream of the wind tunnel. Therefore, the temperature difference between the mainstream and the secondary flows should be kept as small as possible. This can be achieved by attaching heated strips on the upstream of the orifice. By adjusting the input voltage, the temperature difference can be maintained within $0.2^{\circ} \mathrm{C}$ during the experiment.

To promote the mainstream turbulence level, a bar grid was installed $460 \mathrm{~mm}$ upstream of the linear cascade, shown in Figure 2. The bar grid which was made of stainless tubes, $15 \mathrm{~mm}$ in diameter and $50 \mathrm{~mm}$ in pitch, has the same cross section of the test section. As a result, the bar grid has a blockage ratio of $45 \%$.

\section{Mass Transfer Model}

The test linear cascade consists of six scaled-up blades, made of aluminum. Counting from the top of the test section, the test blade is the fourth one. Unlike the smooth test turbine blade used in Chen et al. [1994b], there are three rows of injection holes located on the leading edge of the present test turbine blade. Figure 3 shows the schematic view of the leading edge of the test blade. The streamwise distance from the front stagnation line to the rear stagnation line is $S_{s f}=188 \mathrm{~mm}$ on the suction side and $S_{p f}=154 \mathrm{~mm}$ on the pressure side. 


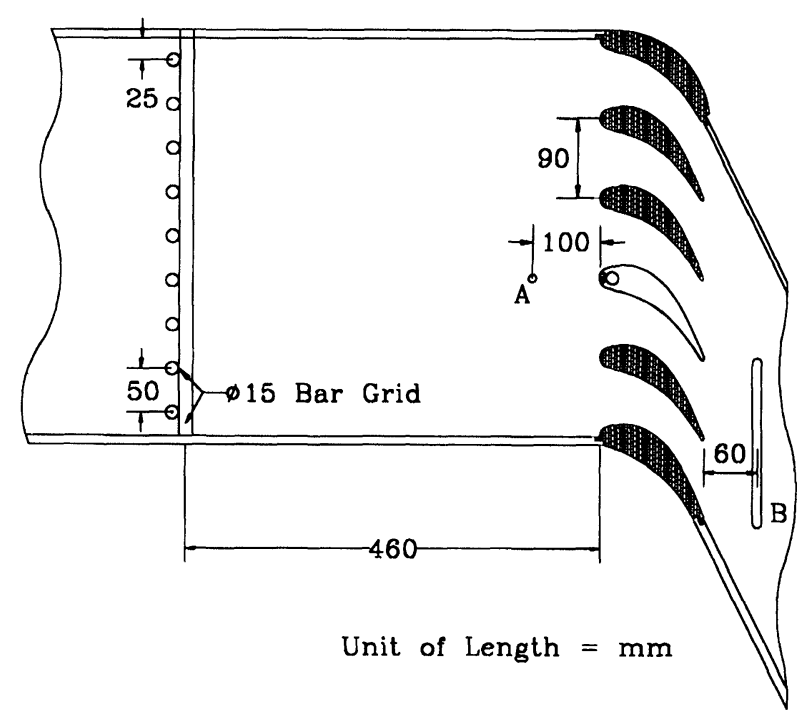

FIGURE 2 Schematic view of the scaled-up blade cascade and the upstream bar grid.

There are three staggered rows of injection holes that are located on the leading edge of the test blade. As shown in
Fig. 3, the locations of the centerline of these three rows of injection holes from the pressure side to the suction side are $S_{p} / S_{p f}=0.088, S_{s} / S_{s f}=0.000$, and $S_{s} / S_{s f}=$ 0.056 . That is, the central row of injection holes is located right on the front stagnation line and denoted as the injection row $S L$ and the others are located on the suction side (row, $S S$ ) and pressure side (row, $P S$ ) of the test blade, respectively. Each row has seven equallyspaced injection holes with a diameter of $3.33 \mathrm{~mm}$ and a pitch of $10 \mathrm{~mm}$. The ratio of the injection hole length to the diameter is 3.5 . In the wind tunnel, secondary flows are ejected through those injection holes and move toward the endwall. In addition, the injection holes are oriented at 90 degrees and 30 degrees to the test surface in the streamwise and spanwise direction, respectively.

A layer of $1.5 \mathrm{~mm}$ solid naphthalene was coated on a span of $150 \mathrm{~mm}$ of the test blade for conducting the mass transfer run. For determining the diffusion coefficient of naphthalene vapor in the air during the run, a T-type thermocouple was embedded underneath the surface of solid naphthalene to measure the naphthalene temperature. A circular secondary flow distributor with a diameter of $10 \mathrm{~mm}$ was inserted into the hollow chamber of

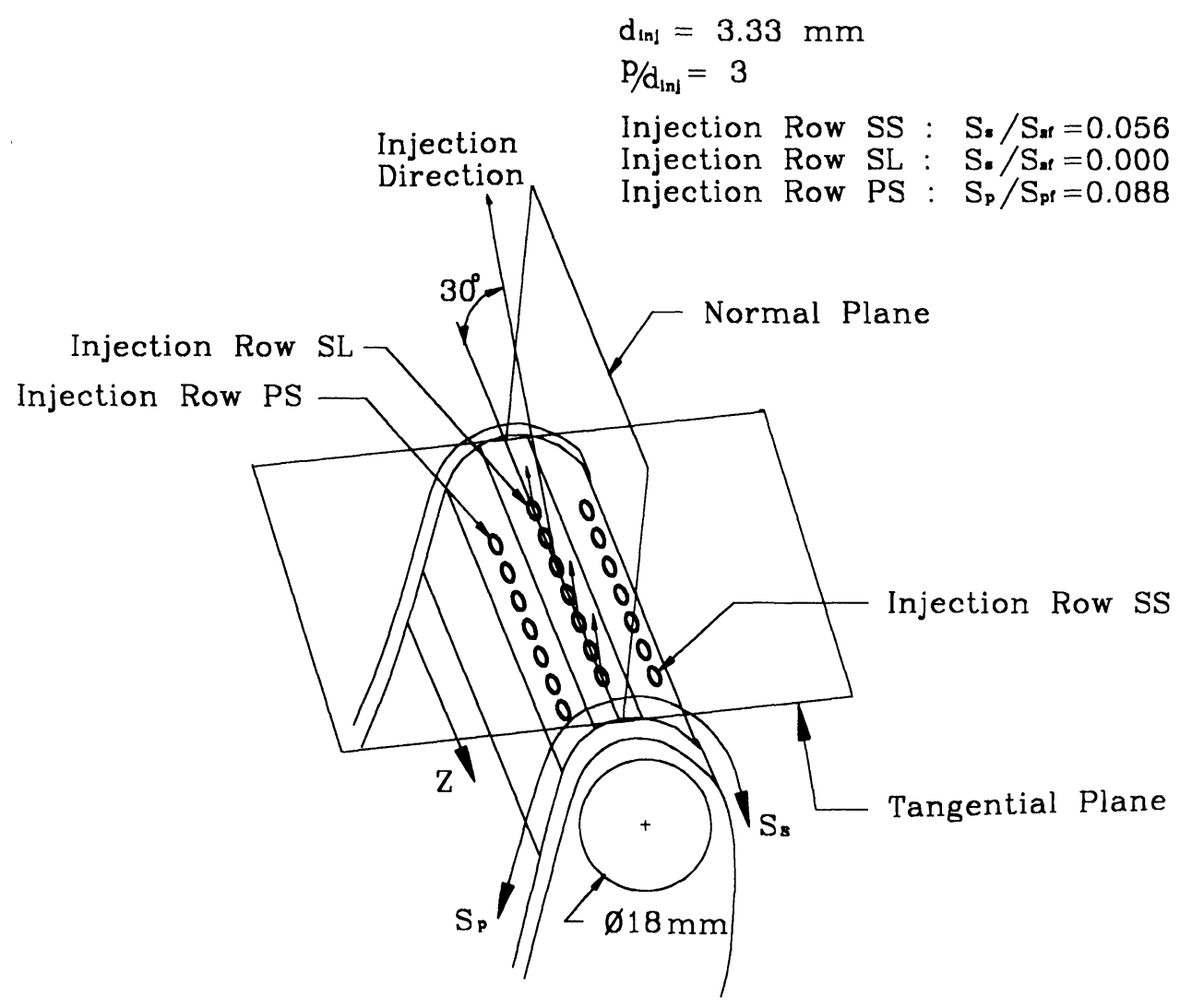

FIGURE 3 Schematic view of the leading edge region of the test turbine blade. 
the leading edge to ensure the uniform distribution of secondary flows ejected through the injection holes.

\section{Instrumentation}

The local mass transfer rate was determined from the sublimation depth of the coated naphthalene surface on the test blade after it was exposed in the mainstream for a period of time. To measure the sublimation depth, a PC-controlled four-axis auto-measuring system was used and described in details in previous studies (Chen et al., 1994a; (Chen et al.,) 1994b). The present study implements a "Labview" software package that was developed by Texas Instrument Co. for controlling the four stepping motors and recording the measured data of the naphthalene surface profile of the test blade.

To conduct the surface profile measurement, the test blade coated with a layer of naphthalene is installed on a four-axis positioning table. The surface profile of the coated naphthalene layer can be determined from the voltage readings of a depth gauge (LVDT) as the gauge is moved to the designated location. All locations to which the gauge should be moved for surface profile measurements are already stored in a data file in advance. These voltage readings are first transmitted to a multimeter, model HP 3478A, and then are recorded in the hard-disk of a Macintosh IIx computer.

Furthermore, the measurements of the streamwise velocity and the mainstream turbulence level were performed by a pitot tube and a TSI Model IFA-100 constant-temperature anemometer with a Model 1210T1.5 hot-wire probe, respectively.

\section{Data Analysis}

The naphthalene sublimation depth on the test blade surface can be evaluated from both naphthalene surface profiles before and after the test blade was placed in the wind tunnel. In the wind tunnel, the test blade surface was exposed to both mainstream and secondary flows for a period of time. The naphthalene vapor is absent in both the approaching mainstream and secondary flows. Once the sublimation depth at every designated location was obtained, the local mass transfer coefficient can be determined from

$$
h_{m}=\frac{L_{s b} \rho_{s}}{\rho_{1 \cdot u} \Delta t}
$$

where $L_{s b}$ is the naphthalene sublimation depth, $\rho_{s}$ is the density of solid naphthalene, $\rho_{v, n}$ is the density of naphthalene vapor over the test blade surface, and $\Delta t$ is the duration of a typical mass transfer run as the test blade is exposed to the air-stream in the wind tunnel. The mass transfer coefficient can be nondimensionalized as a Sherwood number,

$$
S h=\frac{h_{m} C}{D_{f}}
$$

where $C$ is the chord length of the turbine blade and $D_{f}$ is the diffusion coefficient of naphthalene in air. The value $D_{f}$ is determined by an empirical correlation in Cho et al. [1994], given by

$$
D_{f}=0.0681\left(\frac{T_{1, w}}{298.16}\right)^{1.93}\left(\frac{760}{P_{a t m}}\right)
$$

\section{Test Conditions and Uncertainty Analysis}

For all mass transfer measurements, the exit Reynolds number, remaining at a constant value of 397,000 , was based on the chord length of the test blade and the exit velocity of the planar cascade. The mainstream turbulence level for the no-grid and bar grid cases is $0.4 \%$ and $6.0 \%$, respectively. As the secondary flows are introduced, the mass transfer measurements were conducted at four different averaged blowing ratios of 0.6, 0.8, 1.0, and 1.2; these blowing ratios were determined from the total mass flow ejected through all the injection holes. As the secondary flows were ejected through injection holes, the ejected jets were not evenly distributed through the three rows of injection holes and the ratio in velocity varied with the blowing ratio. By assuming that the air density in the ejected jets from each injection row is the same as the mainstream air density, the centerline velocity at the exit of each injection row was measured by a pitot tube probe with a diameter of $2 \mathrm{~mm}$. Results show that the variation of centerline velocity was within $\pm 6 \%$ for all tests. Consequently, the apparent blowing ratio at each injection hole was evaluated from the measured velocity and their values were listed in Table 1.

For each run, the mass transfer results were measured at 74 locations along the streamwise direction of the test blade; 39 on the suction side and 35 on the pressure side. On each streamwise location, there are 25 equally-spaced measured points along the spanwise direction, spanning from $Z=61 \mathrm{~mm}$ to $Z=97 \mathrm{~mm}$ with a spacing of 1.5 $\mathrm{mm}$. Note that the $Z$ coordinate is normal to the endwall. The local results within the region whose span covers three neighboring holes from $Z=61 \mathrm{~mm}$ to $Z=91 \mathrm{~mm}$ were used to evaluate the spanwise-averaged Sherwood number $(\overline{S h})$.

Based on the $95 \%$ confidence level and the equation proposed by Kline and McClintock [1953], the uncertainty of each measured quantity was estimated and 
TABLE 1

Apparent blowing ratio on each injection row

\begin{tabular}{ccccccc}
\hline & \multicolumn{2}{c}{ Injection Row SS } & \multicolumn{2}{c}{ Injection Row $S L$} & \multicolumn{2}{c}{ Injection Row PS } \\
$M$ & $M_{l}(T u=0.4 \%)$ & $M_{l}(T u=6.0 \%)$ & $M_{l}(T u=0.4 \%)$ & $M_{l}(T u=6.0 \%)$ & $M_{l}(T u=0.4 \%)$ & $M_{l}(T u=6.0 \%)$ \\
\hline 0.6 & 0.51 & 0.66 & 0.69 & 0.48 & 0.60 \\
0.8 & 0.69 & 0.84 & 0.93 & 0.72 & 0.78 \\
1.0 & 0.87 & 0.99 & 1.17 & 0.96 & 0.96 \\
1.2 & 1.05 & 1.02 & 1.41 & 1.17 & 1.05 \\
\hline
\end{tabular}

listed in Table 2. In addition, the repeatability of the mass transfer measurement was checked by conducting several experiments for each test case.

\section{RESULTS AND DISCUSSION}

The measured results are presented and discussed in two parts for various test conditions: the streamwise distributions of the spanwise-averaged Sherwood number and the spanwise distributions of the local Sherwood number over both surfaces of the test blade. Of particular interest is the effects of the blowing ratio and the mainstream turbulence level on the local mass transfer distributions in regions near the injection holes. Results are also compared with the published data in Chen et al. [1994b] over a smooth turbine blade without film cooling holes.

\section{Spanwise-Averaged Mass Transfer Distributions}

Figures 4(a) and 4(b) respectively show the effect of the blowing ratio on the spanwise-averaged mass transfer distributions over the suction surface of the test blade for the blowing ratio ranging from $M=0.6$ to $M=1.2$ at $T u$ $=0.4 \%$ and $6.0 \%$. Over the pressure surface, Figures 5 (a) and 5(b) illustrate the influence of the blowing ratio on the spanwise-averaged Sherwood number distributions at $T u=0.4 \%$ and $6.0 \%$, respectively. In these Figures, two arrows on the horizontal axis indicate the streamwise locations of the central position of the injection rows. For comparison, the measured results without injection holes in Chen et al. [1994b], indicated by the solid symbols, are also shown in Figures 4 and 5 . Note that both mass transfer measurements with or without film cooling holes were obtained over the test blade with the same profile at the same approaching mainstream condition.

For results without film cooling holes at $T u=0.4 \%$, a sharp decrease in mass transfer over the suction surface is due to the laminar boundary-layer flow developing on the blade surface, as shown in Figure 4(a). Further downstream, the mass transfer rate reaches a minimum value around $S_{s} / S_{s f} \approx 0.84$ due to the separation of the boundary-layer flow. Beyond the separation point, the mass transfer rate increases rapidly due to the incident of separated-flow transition. An increase in the approaching mainstream turbulence level results in an early transition of the boundary-layer flow. Detailed discussions about the effect of the mainstream turbulence level on the boundary-layer transition over the blade surface are described in Mayle [1991].

As shown in Figures 4(a) and 4(b), it is obvious that the existence of secondary flows significantly enhance the mass transfer rate over the suction surface of the test blade. In the regions downstream of the injection row SS, the measured mass transfer rate for cases with secondary flows is more than twice as high as that without secondary flows. Regardless of the mainstream turbulence level, the onset of the transition point, indicated by the minimum value of $\overline{S h}$, also moves closer upstream near the location of $S_{s} / S_{s f} \approx 0.48$ with the presence of secondary flows. Both the enhancement of the mass transfer rate and the early transition of the boundary-layer flow over the suction surface are due to the promotion of turbulence level in the free-stream by the interaction of the secondary flows and the mainstream.

Near the leading edge, two local minimum values in the $\overline{S h}$ distribution are found at the locations just down-

TABLE 2

Estimated uncertainties for measured quantities

\begin{tabular}{lccccccc}
\hline Parameter & $M$ & $R e_{2}$ & $S h$ & $T_{2}\left(T_{\infty}\right)$ & $T u$ & $U_{\infty}$ & $U_{2}$ \\
\hline Quantity & 1.2 & 397000 & 640 & $300 \mathrm{~K}$ & $0.4 \%$ & $17.05 \mathrm{~m} / \mathrm{s}$ & $41.02 \mathrm{~m} / \mathrm{s}$ \\
Uncertainty & $\pm 5.0 \%$ & $\pm 0.5 \%$ & $\pm 6.0 \%$ & $\pm 0.2 \mathrm{~K}$ & $\pm 5.0 \%$ & $\pm 0.5 \%$ & $\pm 0.5 \%$ \\
\hline
\end{tabular}



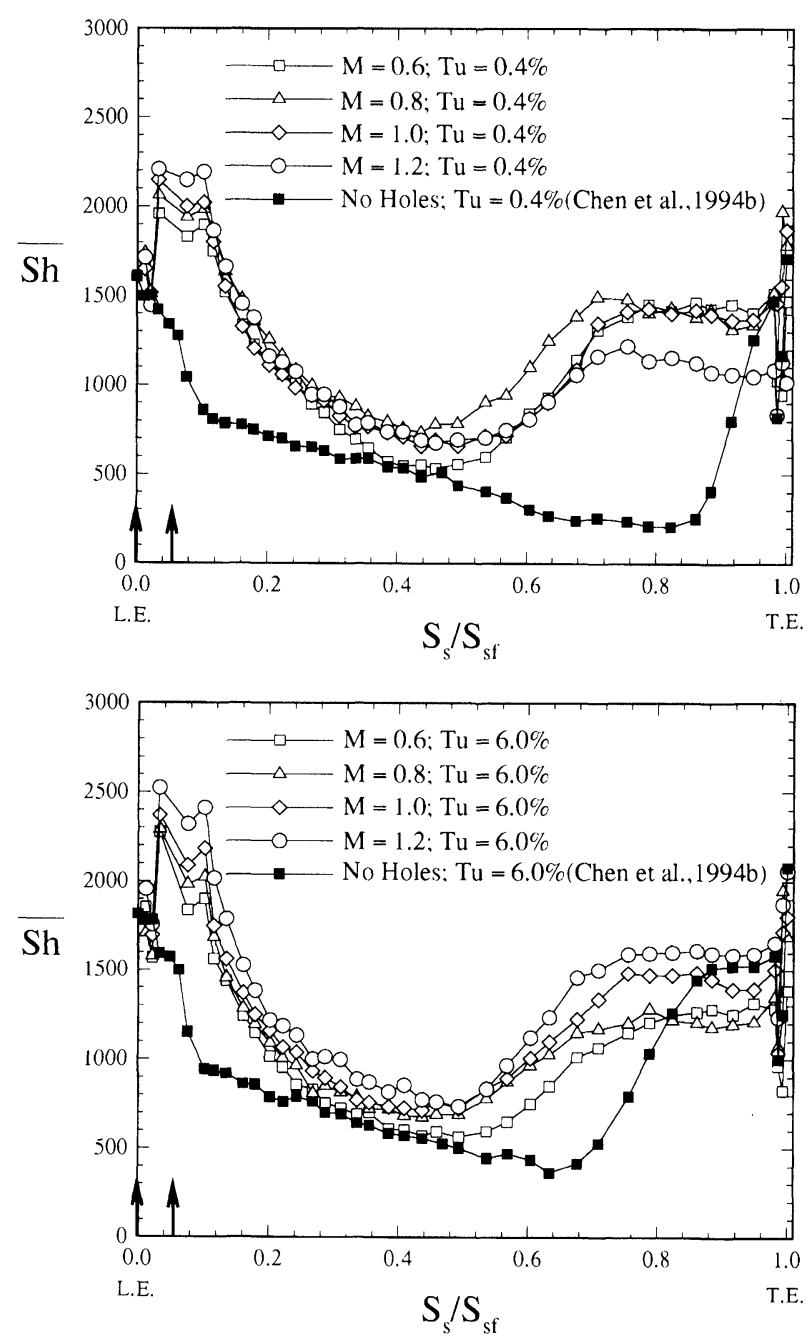

FIGURE 4 Effect of blowing ratio on the streamwise distributions of spanwise-averaged mass transfer rate over the suction surface at (a) $T u$ $=0.4 \%$, (b) $T u=6.0 \%$.

stream of the injection rows $S L$ and $S S$. Both minimum values could be caused by the small recirculated eddies which are formed as the free-stream flows over the strong jets ejected in the spanwise direction.

It can also be observed from Figure 4(a) that the secondary flows have a stronger influence on the mass transfer rate over the suction surface than the approaching mainstream turbulence level. Beyond the onset of the transition point, the measured spanwise-averaged mass transfer rate does not increase with the blowing ratio over the suction side at $T u=0.4 \%$. Among all the blowing ratios conducted in the present study, the mass transfer rate is the highest at $M=0.8$ but the lowest at $M$ $=1.2$. As the approaching mainstream turbulence level is low, the secondary flows do not mix quickly enough with the free-stream in the blade cascade so that the mass transfer rates directly affected by the ejected jets can be traced over the entire suction surface. A proof of the aforementioned will be given in the later section using periodic variations in the spanwise distributions of local mass transfer rate measured at all the streamwise locations.

Over the suction surface, the ejected jets themselves are more dominant in affecting the mass transfer rate than the promotion of the free-stream turbulence level by mixing the jets and the free-stream. As the secondary flows are ejected from the injection holes, the jets with a smaller blowing ratio can stay closer over the blade surface which results in a higher mass transfer rate. However, the turbulence level at the exit of the injection holes is higher for the secondary flows with a larger blowing ratio [Ou et al., 1992; Menhedale and Han, 1992]. Downstream of the injection holes, the mass transfer rate increases with the turbulence level in the free-stream that is promoted by the secondary flows. However, the trend for increasing the mass transfer rate by increasing the blowing ratio is opposite for both the jets coverage on the surface and the free-stream turbulence level. Therefore, the highest value in $\overline{S h}$ does not always occur at the same blowing ratio over the entire suction surface. Within the region just downstream of the injection holes, the mass transfer rate increases with the blowing ratio. Further downstream beyond the onset of transition point, the mass transfer rate at $M=0.8$ is the highest among all tests.

Figure 4(b) illustrates that the increase in the mass transfer rate is associated with the increase in the blowing ratio. As the approaching mainstream turbulence level is high, the mixing between the free-stream in the blade cascade and the jets is quicker than that at the low turbulence level. Therefore, the turbulence level at the exit of the injection holes becomes the sole dominant factor for affecting the mass transfer rate. Near the leading edge, two local minimum values in the streamwise $\overline{S h}$ distributions can be observed; one is at $S_{s} / S_{s f}=$ 0.022 between the injection row $S L$ and the injection row $S S$ and the other is at $S_{s} / S_{s f}=0.076$ just downstream of the injection row $S S$. Such phenomena are attributed to the formation of recirculated eddies which are caused by the boundary-layer stream flowing over the strong ejected jets, acting like solid blocked bodies.

Over the pressure surface at $T u=0.4 \%$, the mass transfer rate without the film cooling holes decreases from the stagnation line and reaches a minimum value at the separation point near $S_{p} / S_{p f} \approx 0.120$, as shown in Figure 5(a). The short separation bubble quickly reattaches on the pressure surface. Beyond the reattachment 

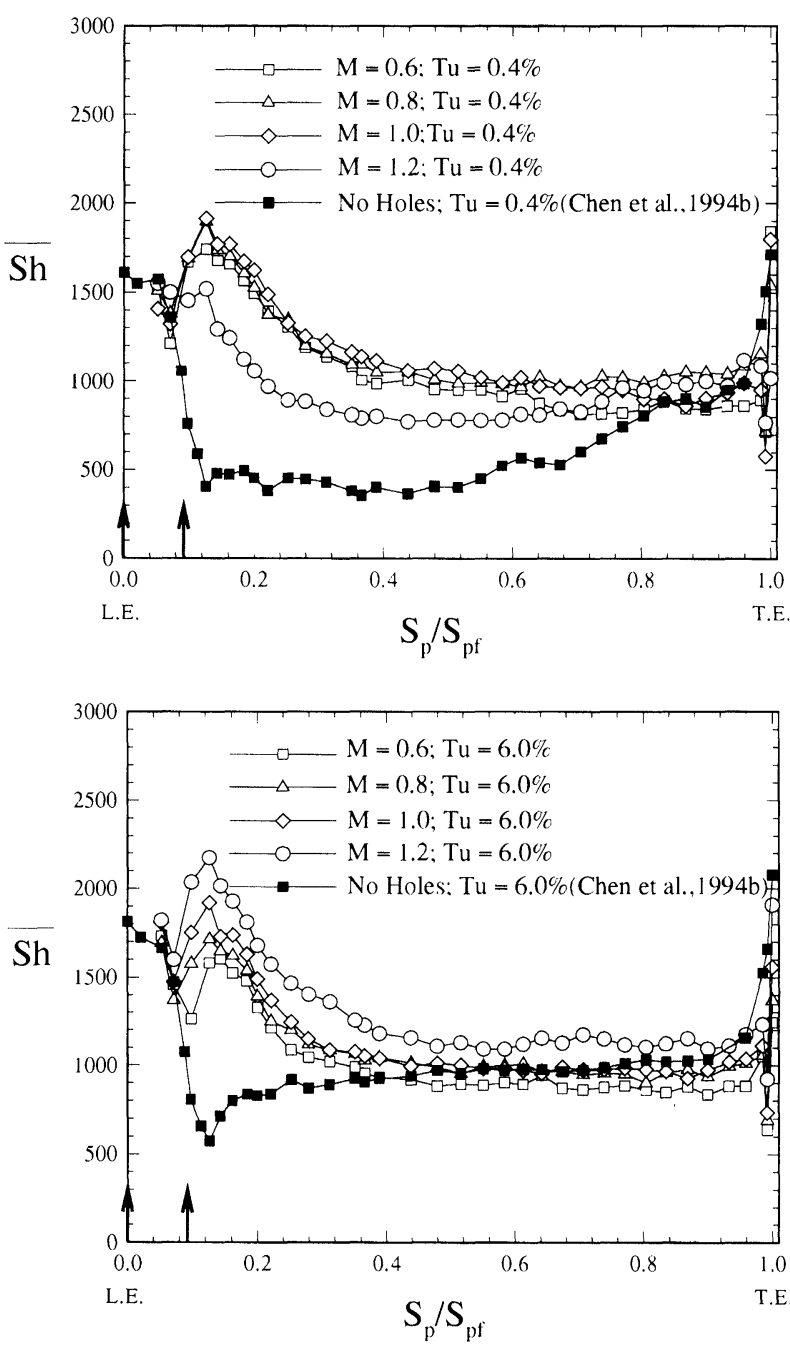

FIGURE 5 Effect of blowing ratio on the streamwise distributions of spanwise-averaged mass transfer rate over the preseure surface at (a) $T u$ $=0.4 \%$, (b) $T u=6.0 \%$.

point, the mass transfer rate gradually increases due to the relaminaration of the turbulent boundary-layer flow and the formation of the Taylor-Görtler vortices [Chen et al., 1994b]. With the presence of the shower-head film cooling, the mass transfer rate increases with the blowing ratio in the region immediately downstream of the injection row $P S$ except for the case at $M=1.2$ and $T u$ $=0.4 \%$. Figure $5(\mathrm{~b})$ also illustrates that there is only a small difference between the spanwise-averaged mass transfer rate enhanced by the intensification of approaching mainstream turbulence level and that by the presence of secondary flows if $M \leq 1$ for the location beyond $S_{p} / S_{p f}=0.489$. However, it should be noted that the mechanism for raising the mass transfer rate is quite different between both cases. The spanwise distribution of the local mass transfer rate, shown in the later section, will illustrate that a large variation still exists within the region for $S_{p} / S_{p f}>0.489$ due to the presence of secondary flows; a uniformly spanwise distribution was found in the same region for the test blade without secondary flows [Chen et al., 1994b]. For verifying the numerical predictions, it requires to identify which mechanism really affects the mass transfer over the blade surface even with a good agreement in the streamwise distribution of the spanwise-averaged mass transfer rate. At $T u=$ $0.4 \%$, shown in Figure 5(a), the lowest mass transfer rate occurs for the case at $M=1.2$ among all conducted blowing ratios. Such a phenomenon is caused by the lift-off of the ejected jets with the high blowing ratio from the pressure surface.

As the approaching mainstream level is raised from $0.4 \%$ to $6.0 \%$, Figure 5 (b) reveals that the mass transfer rate always increases with the blowing ratio for the range of blowing ratios being tested. Nevertheless, the effect of the secondary flows on the mass transfer rate is only significant within the region near the injection holes for $S_{p} / S_{p f}<0.489$

It is well-known that the heat or mass transfer rate over a test surface increases with the increasing of the approaching mainstream turbulence level. This is not true for the mass transfer rate over a turbine blade with the shower-head film cooling. Over the suction surface, the effect of the mainstream turbulence level on the mass transfer distributions are exhibited in Figures 6(a) to 6(d) at various blowing ratios. Within the region beyond the onset of the transition point, the increase in the freestream turbulence level in the blade cascade causes higher spanwise-averaged mass transfer rates for the large blowing ratio at $M \geq 1.0$. The reason for such a phenomena is that the presence of ejected jets is a more dominant factor for affecting the mass transfer rate than the promotion of free-stream turbulence level. As the mainstream turbulence level is low, the ejected jets at the low blowing ratio do not completely mix with the free-stream in the blade cascade and remain attached over the blade surface. As a result, at the same blowing ratio, the augmentation of the mass transfer rate by the secondary flows with distinct jet behaviors at $T u=0.4 \%$ is higher than that of completely mixed flows between the jets and the free-stream at $T u=6.0 \%$. A similar trend regarding the effect of the mainstream turbulence level on the blade mass transfer rate can also be observed over the pressure surface through a careful examination on the results illustrated in Figures 5(a) and 5(b). The same phenomena were also demonstrated in Ou et al. [1992]: 

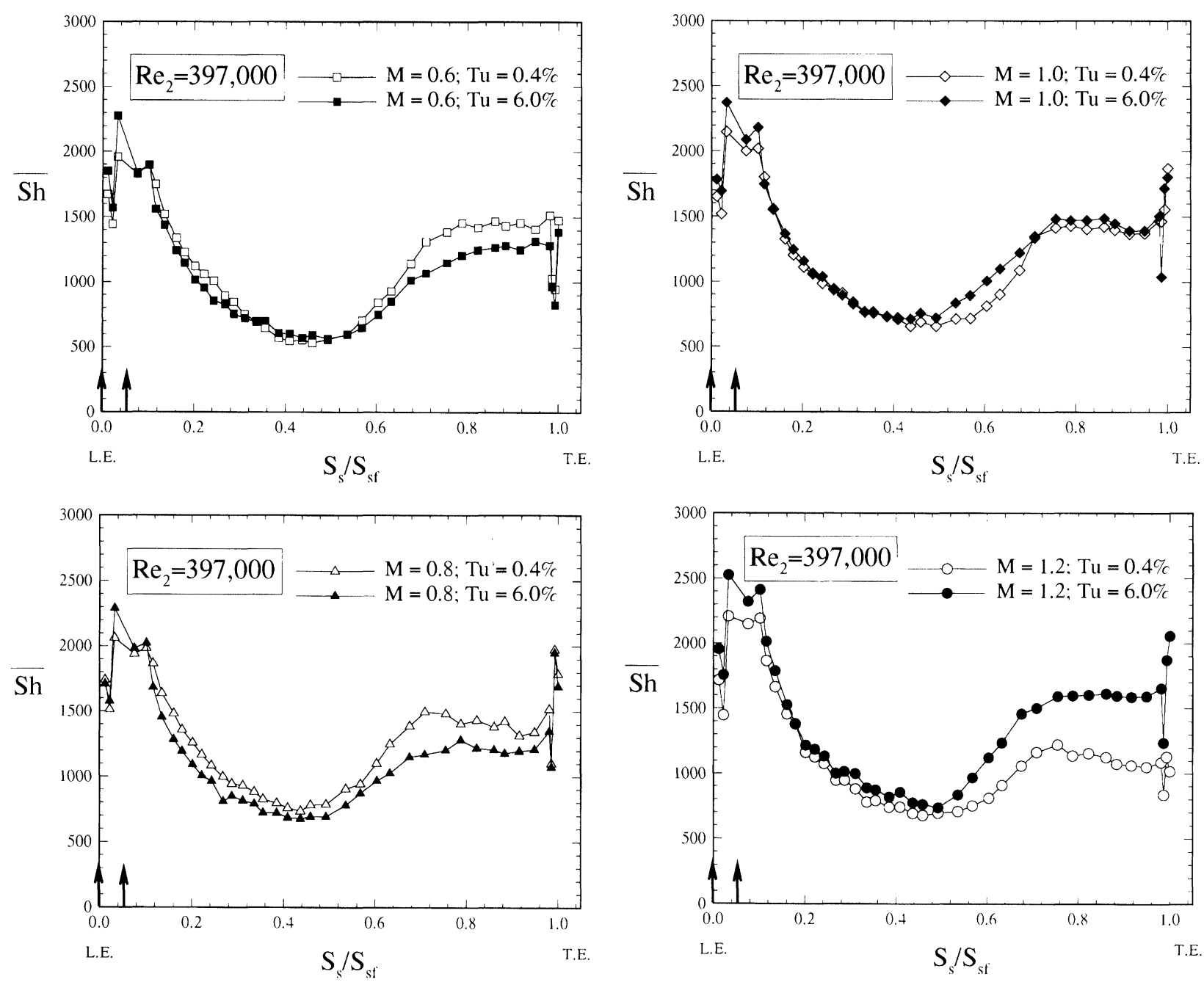

FIGURE 6 Influence of mainstream turbulence level on the streamwise $\overline{S h}$ distributions over the suction surface:(a) $M=0.6,(\mathrm{~b}), M=0.8,(\mathrm{c})$ $M=1.0$, and (d) $M=1.2$.

the heat transfer rate with the stagnation film cooling may be lower even with an increase in the mainstream turbulence level.

\section{Spanwise Distributions of Local Mass Transfer}

On the suction surface, Figures 7(a) to 7(d) show the spanwise distribution of the local Sherwood number at different streamwise locations at $T u=0.4 \%$ and $M=$ 0.8 . Note that the arrows on the horizontal axis indicate the hole locations of the injection row $S L$ in Figure 7(a) and those of the injection row $S S$ in Figures 7(b) to 7(d). Measured results between the injection rows $S L$ and $S S$ are illustrated in Figure 7(a). Within such a short region, the variation in the mass transfer rate is quite large and a local minimum value occurs at the location of $S_{s} / S_{s f}=$
0.022. As the mainstream flows over the two neighboring jets ejected through the injection rows of $S S$ and $S L$, a recirculated flow is expected to occur in the region between the two jets resulting in the local minimum value at $S_{s} / S_{s f}=0.022$.

As shown in Figure 7(a) to 7(d), it can be observed that the large and periodic variations in the local mass transfer distributions exist for most streamwise measured locations. Besides, the peak mass transfer rates do not align with the centerlines of injection holes because the secondary flows are ejected in the spanwise direction towards the endwall. Just downstream of the injection row $S L$ at $S_{s} / S_{s f}=0.102$, the maximum value of the spanwise mass transfer rate distribution can be more than twice as large as the minimum value. Furthermore, the spanwise mass transfer rate distributions also exhibit a 

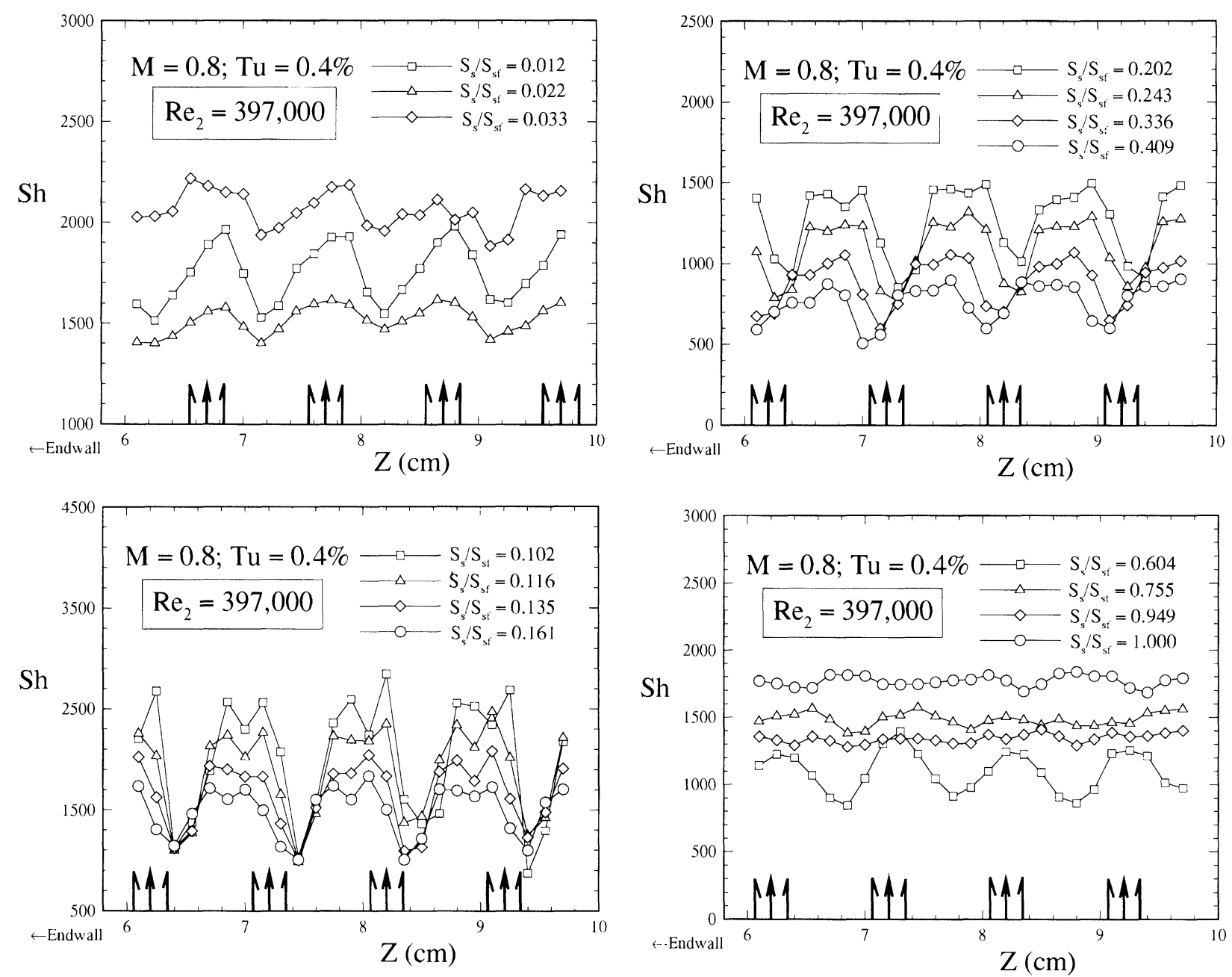

FIGURE 7 Spanwise distributions of local mass transfer rate over the suction surface at $T u=0.4 \%$ and $M=0.8$ :(a) $S_{s} / S_{s f}=0.012-0.033$, (b) $S_{s} / S_{s f^{\circ}}=0.102-0.161$, (c) $S_{s} / S_{s f}=0.202-0.409$, and (d) $S_{s} / S_{s f}=0.604-1.0$

periodic behavior with the same wavelength as the pitch of the injection rows. In the region with the span of one pitch of injection holes, the mass transfer rate reaches its minimum value just above the injection holes, then sharply rises to a peak value. After the first peak, another peak following a small dip occurs in the local mass transfer rate distribution. Finally, the mass transfer rate dramatically drops to the minimum value. The measured results demonstrate a peculiar phenomenon that shows twin peak values in the local mass transfer rate, caused by a single ejected jet. The reason for causing such a peculiar behavior is that a pair of counter-rotating vortices are formed in the single ejected jet even within a row of injection holes, as shown in Figure 8. Further downstream, the twin peaks start to merge as a single peak, resulting from the lateral mixing of the jets and the

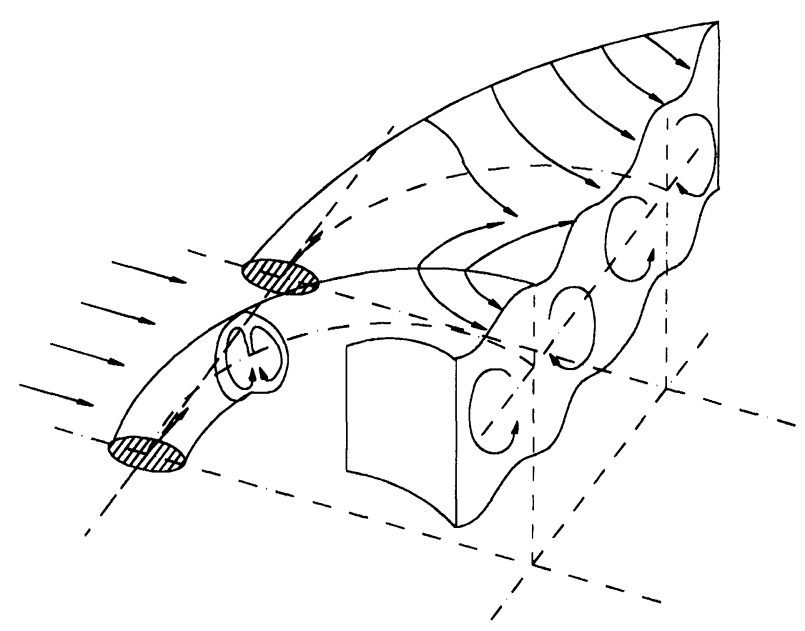

FIGURE 8 Sketch of bound vortices for a row of jets [Kurse, 1985]. 
mainstream. With the increase of the streamwise distance, the single peak moves towards the endwall as the ejected jets travel downstream. Moreover, the trace of periodical variation in local mass transfer is still visible even in the transition region at $S_{s} / S_{s f}=0.755$, as shown in Figure $7(d)$. Near the trailing edge, the ejected jets are completely mixed with the mainstream.

As compared with the measured results conducted by Chen et al. [1994b] on the smooth turbine blade, some periodic and large spanwise variations in local mass transfer rates appear in the region of $S_{s} / S_{s f}=0.919$ to $S_{s} / S_{s f}=0.986$ without the film cooling holes but disappear at the same region with the shower-head film cooling at $T u=0.4 \%$, as shown in Figure 7(d). Near the trailing edge of the smooth turbine blade, such a periodic behavior in the local mass transfer is caused by the $\Lambda$ vortices induced by the secondary instability in the
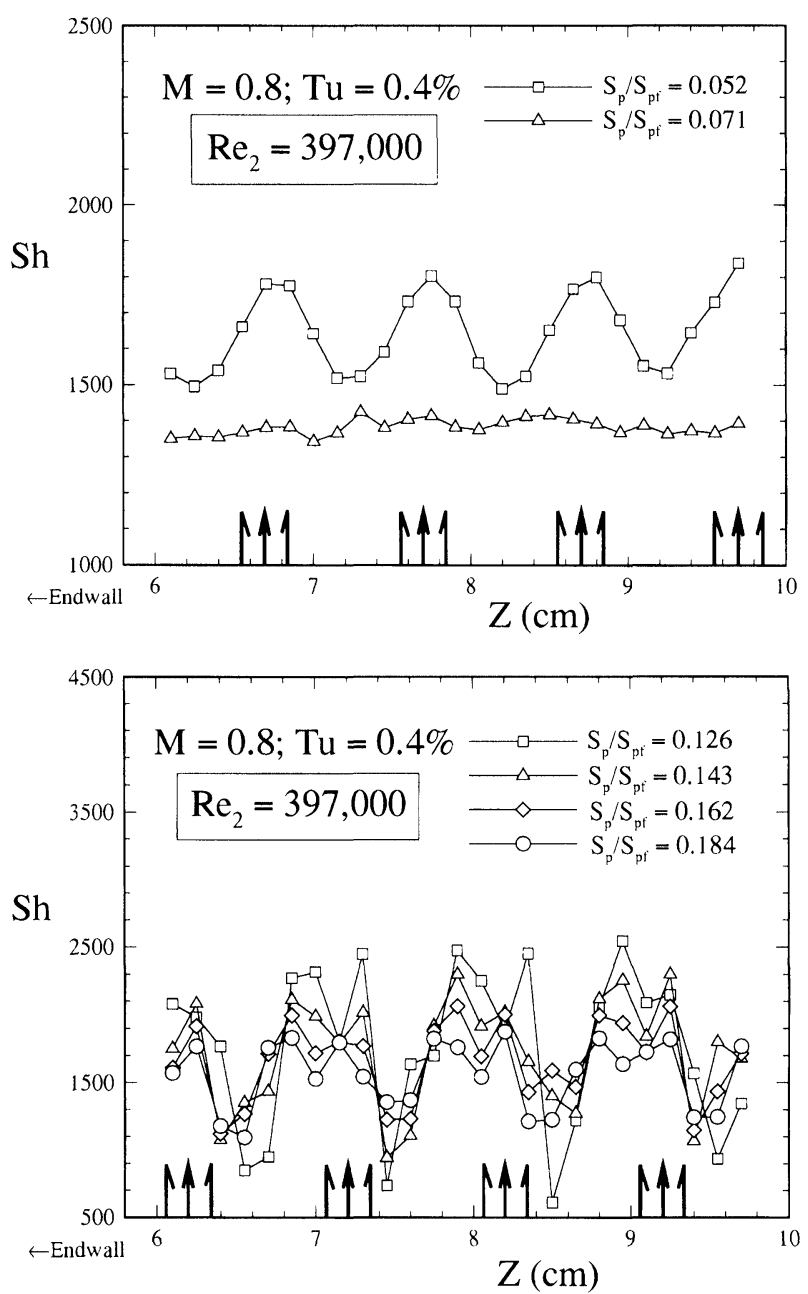

separated transition process. The disappearance of the periodic behavior indicates that promotion of the freestream turbulence level in the blade cascade due to the interaction between the ejected jets and the mainstream results in the bypass transition instead of the separated transition; a transition process usually occurs in the boundary-layer flow over the suction surface with a low turbulence level in the approaching mainstream.

Figure 9(a) shows the spanwise distribution of the local mass transfer rate on the pressure side in the region between the injection rows $S L$ and $P S$ at $M=0.8$ and $T u$ $=0.4 \%$. A rather smooth mass transfer distribution is found at $S_{p} / S_{p f}=0.071$ and its value is relatively low as compared with the results at $S_{p} / S_{p f}=0.052$. The reason for such a phenomenon is the same as that for causing a local minimum at $S_{s} / S_{s f}=0.022$ over the suction surface. As the mainstream flows over two rows of ejected jets
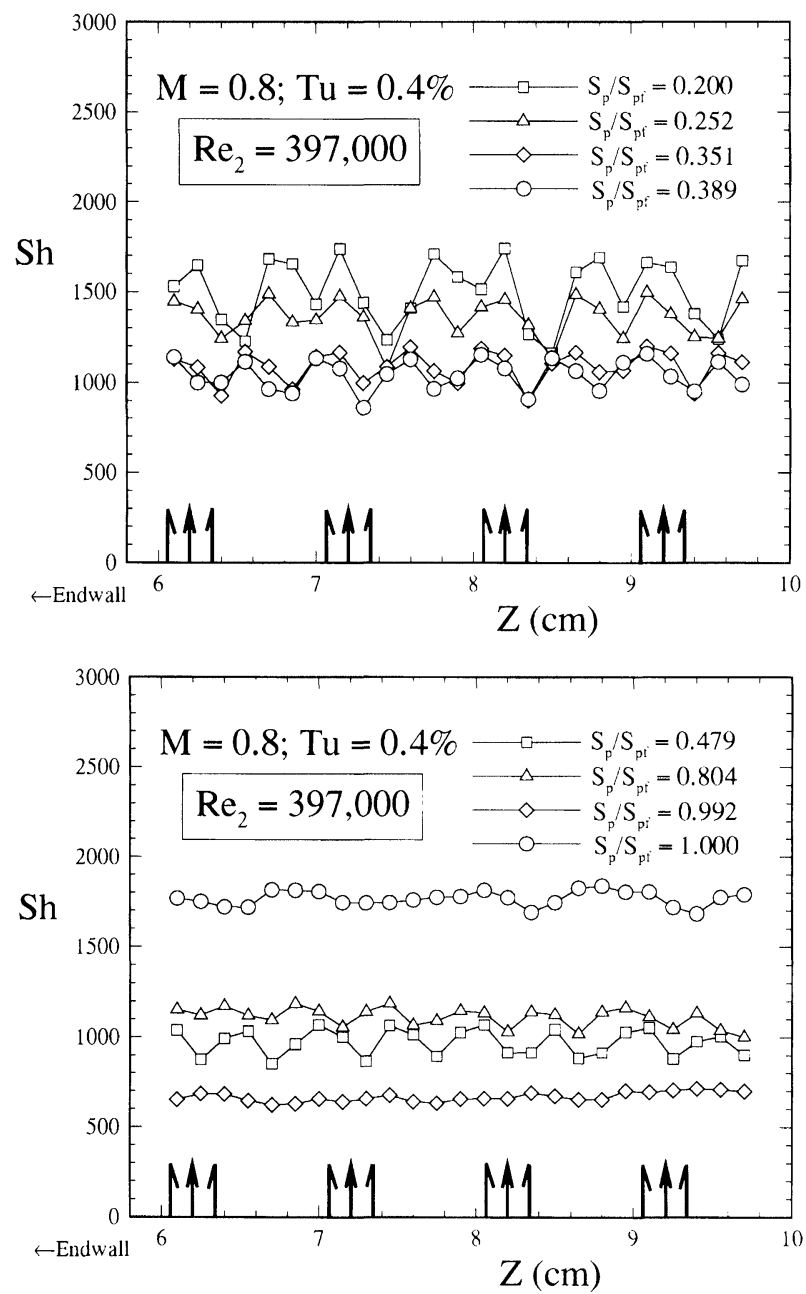

FIGURE 9 Spanwise distributions of local mass transfer rate over the pressure surface at $T u=0.4 \%$ and $M=0.8:\left(\right.$ a) $S_{p} / S_{p f}=0.052-0.071$, (b) $S_{p} / S_{p f}=0.126-0.184$, (c) $S_{p} / S_{p f}=0.200-0.389$, and (d) $S_{p} / S_{p f}=0.479-1.0$. 
acting like two solid ribs, a recirculated flow region is formed in the region between the two rows of ejected jets. The recirculated flow is the dominant factor that affects the mass transfer rate in such a region. Therefore, the distinct behavior of periodic variation in the local mass transfer does not appear at $S_{p} / S_{p f}=0.071$.

Downstream of the injection row $P S$ to the trailing edge, the measured local mass transfer results are presented in Figures 9(b) to 9(d) at $M=0.8$ and $T u=0.4 \%$. Since the boundary-layer flow experiences the favorable pressure gradient in the region from $S_{p} / S_{p f} \approx 0.1$ to $S_{p} / S_{p f}$ $\approx 0.9$, the mixing of secondary flows with the mainstream on the pressure surface is not as quick as that on the suction surface. Therefore, distinct twin peaks in the mass transfer rates, caused by the counter-rotating vortices in a single jet, exists continuously from $S_{p} / S_{p f}=$ 0.126 to $S_{p} / S_{p f}=0.804$. The trace of ejected jets with such twin-peak behavior is extended by increasing the blowing ratio. In addition, the measured results in Chen et al. [1994b] indicate the formation of the Taylor-Görtler vortices that produce periodic variations with a wavelength of $9 \mathrm{~mm}$ in the local mass transfer distributions from $S_{p} / S_{p f}=0.479$ to the trailing edge on the smooth turbine blade at $T u=0.4 \%$. As the secondary flows are present, the promotion in the mainstream turbulence level may result in the disappearance of the TaylorGoörtler vortices on the pressure surface.

Figures 10(a) to 10(d) illustrate the spanwise distributions of the local Sherwood number at $M=0.8$ and $T u=$ $6.0 \%$ over the suction surface. By increasing the mainstream turbulence level, the variation in the local mass transfer rate is not so severe as that in the local mass transfer results at $T u=0.4 \%$. Downstream of the injection row $S L$, the distinct twin peaks in the mass
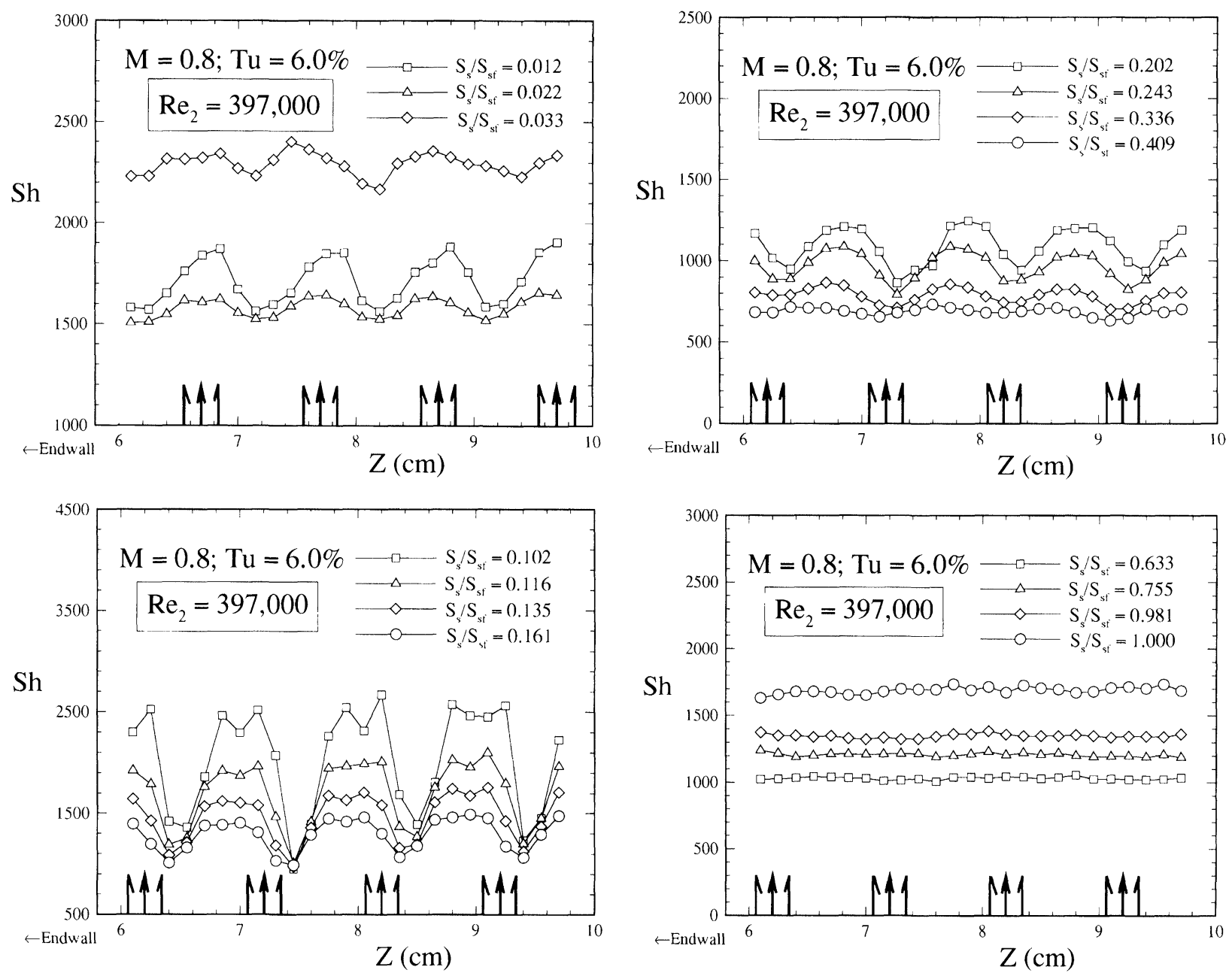

FIGURE 10 Spanwise distributions of local mass transfer rate over the suction surface at $T u=6.0 \%$ and $M=0.8:\left(\right.$ a) $S_{s} / S_{s f}=0.012-0.033$, (b) $S_{s} / S_{s f}=0.102-0.161$, (c) $S_{s} / S_{s f}=0.202-0.409$, and (d) $S_{s} / S_{s f}=0.633-1.0$. 
transfer also merge more quickly than that of the case at the low turbulence level. Increasing the streamwise distance, the complete disappearance of the periodic behavior in the local Sherwood number distribution at $S_{s} / S_{s f}=0.633$ indicates that the ejected jets and the mainstream are well mixed. Downstream of the location of $S_{s} / S_{s f}=0.633$, the time-averaged characteristics of the transitional boundary-layer flow is two-dimensional in space. In Figure 4(b), a gradual rise in the spanwiseaveraged mass transfer rate illustrates that the boundarylayer flow is still transitional in the region from $S_{s} / S_{s f} \approx$ 0.48 to $S_{s} / S_{s f} \approx 0.8$. Within such a region, no spanwise variation in the local mass transfer distribution is found.

The enhancement of mass transfer results from two mechanisms for the application of the shower-head film cooling. One is the promotion of the mainstream turbulence level due to the mixing between the secondary flows and the mainstream, and the other is the distinct vortices motion in the secondary flows. As the approaching mainstream turbulence level is low, the distinct vortices in the ejected jets are more dominant than the promotion of free-stream turbulence level in the blade cascade for affecting the mass transfer rate. On the other hand, the highly turbulent free-stream becomes the dominant factor as the jets quickly mix with the mainstream at $T u=6.0 \%$. In the case of low blowing ratio, the increase in the mainstream turbulence level may not raise the mass transfer rate because the distinct jet behavior could result in a higher mass transfer rate than the mainstream turbulence level, as shown in Figures 4(a) and 4(b)

The measured mass transfer distributions over the pressure surface at $T u=6.0 \%$ and $M=0.8$ are illustrated in Figures 11(a) to 11(d). As discussed in the
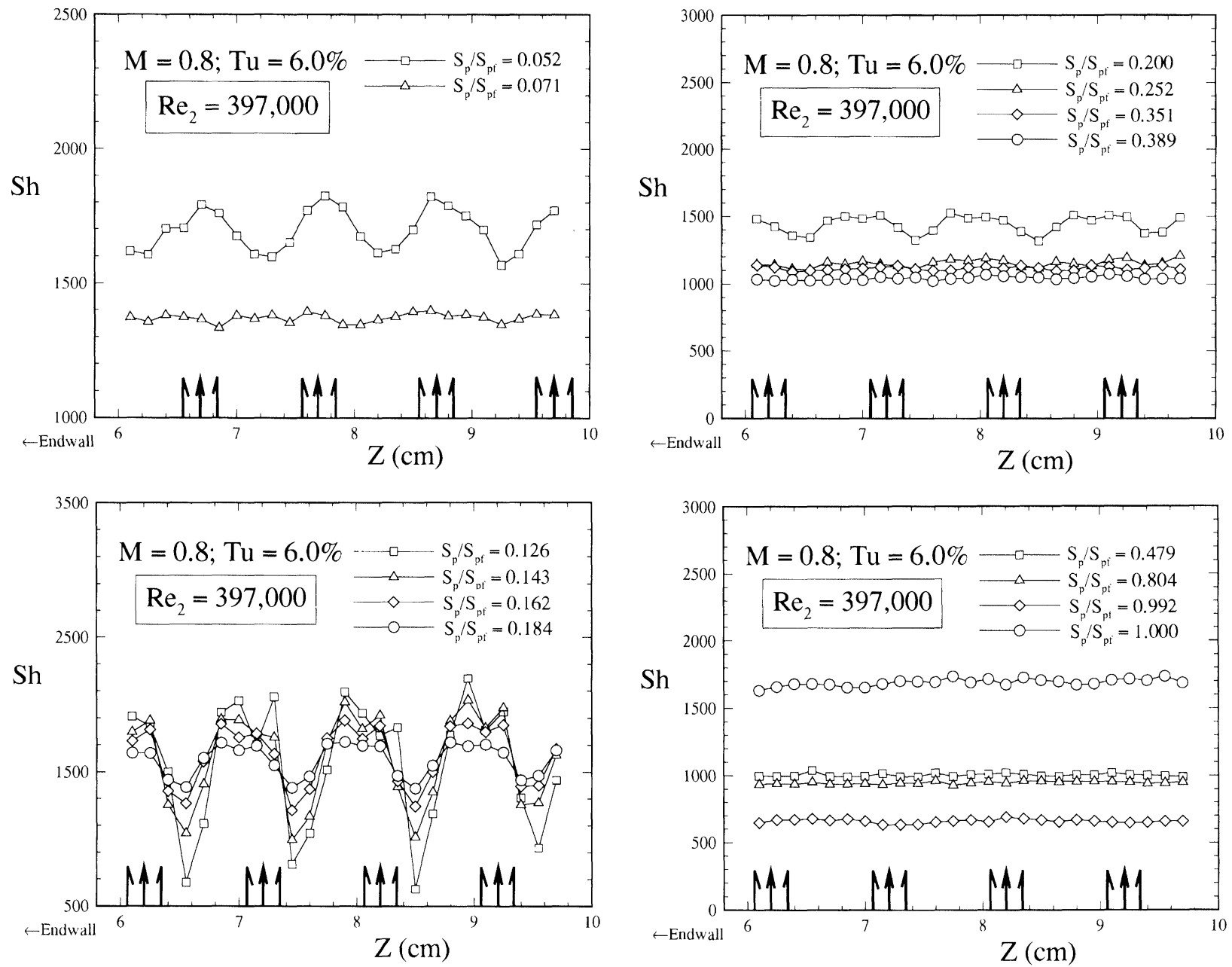

FIGURE 11 Spanwise distributions of local mass transfer rate over the pressure surface at $T u=6.0 \%$ and $M=0.8:(a) S_{p} / S_{p f}=0.052-0.071$, (b) $S_{p} / S_{p f}=0.102-0.184$, (c) $S_{p} / S_{p f}=0.200-0.389$, and (d) $S_{p} / S_{p f}=0.479-1.0$. 
early section, the appearance of twin peaks in the local mass transfer is continuously observed in the region from $S_{p} / S_{p f}=0.126$ to $S_{p} / S_{p f}=0.804$ at $T u=0.4 \%$ and $M=$ 0.8 . Not far from the leading edge, a plateau with a high mass transfer rate is already formed due to the merging of the twin peaks as the approaching mainstream turbulence level is raised from $0.4 \%$ to $6.0 \%$. As shown in Figure 11(c), it is surprising that the jets are already mixed with the free-stream at $S_{p} / S_{p f}=0.252$. That is the main reason why the increasing in the approaching mainstream turbulence level does not result in the enhancement of the mass transfer rate over the pressure surface at $M=0.8$.

\section{CONCLUSIONS}

The spanwise-averaged and local mass transfer distributions on both surfaces of the turbine blade are measured and presented. Of particular interest is the influences of the mainstream turbulence level $(T u=0.4 \%, 6.0 \%)$ and the blowing ratio ranging from 0.6 to 1.2 on the mass transfer distributions. All experiments are performed at the same exit Reynolds number, $R e_{2}=397,000$. The conclusions drawn from the measured results are listed as the following:

1. The presence of secondary flows enhances the mass transfer rates over most portions of both the suction and pressure surfaces except for the region near the trailing edge. Near the injection holes, the effect of secondary flows on the mass transfer rate is quite significant.

2. As the mainstream turbulence level is low, the mass transfer rate over the pressure surface at $M=1.2$ is the lowest among all cases of tested blowing ratios indicating the lift-off of secondary flows from the pressure surface.

3. With the presence of shower-head film cooling, the increase in the approaching mainstream turbulence level does not always enhance the mass transfer rate over both surfaces of the turbine blade as the blowing ratio is low.

4. At $T u=0.4 \%$, the periodically spanwise distributions in the local mass transfer distributions appear almost entirely over the suction and pressure surfaces for the cases at all tested blowing ratios. The evidence indicates that the secondary flows do not mix completely as they travel over most portions of the blade surface. With an increase in the mainstream turbulence level, the uniformly spanwise distributions in the local Sherwood number appear at the locations with much smaller values of $S_{p}$ and $S_{s}$ than those at $T u=0.4 \%$. This indicates that the complete mixing between the secondary flows and the mainstream occurs much closer upstream.

5. In the regions just downstream of the injection rows $S S$ and $P S$, three peak values periodically occurs in the spanwise local mass transfer distribution for $T u=$ $0.4 \%$; two peak values occur near the center line of the injection holes but one appears at the midpoint of two neighboring injection holes. The measured results illustrate that a pair of counter-rotating vortices may be formed in the ejected jets as the flows are ejected from the injection holes.

6 . Within the region for $S_{p} / S_{p f}>0.489$, the spanwiseaveraged mass transfer distributions over the pressure surface at $T u=0.4 \%$ with the secondary flows may only slightly differ from those of $T u=6.0 \%$ without the secondary flows. However, the actual mechanism for increasing the mass transfer rate should be clearly identified from the measurements of the spanwise distributions of the local mass transfer rate. Within the same region, the large periodic variation in the spanwise mass transfer distribution can be still observed for the case with the secondary flows at $T u$ $=0.4 \%$ but uniformly spanwise mass transfer rate distributions are found for the case at $T u=6.0 \%$ without the secondary flows.

\section{Acknowledgments}

The financial support from NSC under the Grant No. NSC 82-0401-0002-030 is deeply appreciated.

\begin{tabular}{|c|c|}
\hline \multicolumn{2}{|c|}{ Nomenclature } \\
\hline C & chord length of the test blade, $=152.1 \mathrm{~mm}$ \\
\hline$D_{f}$ & $\begin{array}{l}\text { diffusion coefficient of naphthalene in air, as } \\
\text { determined from Eq. ( } 3 \text { ) }\end{array}$ \\
\hline$D_{i n f}$ & diameter of injection hole, $=3.33 \mathrm{~mm}$ \\
\hline$h_{m}$ & $\begin{array}{l}\text { local mass transfer coefficient, as determined } \\
\text { from Eq. (1) }\end{array}$ \\
\hline$L_{s b}$ & $\begin{array}{l}\text { local sublimation depth of naphthalene during } \\
\text { the exposure of test blade in an air-stream }\end{array}$ \\
\hline$M$ & blowing ratio, $=\rho_{2} U_{2} / \rho_{\varkappa} U_{\varkappa}$ \\
\hline$M_{l}$ & $\begin{array}{l}\text { apparent blowing ratio on each injection row, } \\
=\rho_{2} U_{21} / \rho_{x} U_{x}\end{array}$ \\
\hline$p$ & pitch of injection holes, $=10 \mathrm{~mm}$ \\
\hline$P_{a t m}$ & atmosphere pressure \\
\hline $\mathrm{Re}_{2}$ & exit Reynolds number, $=U_{2} C / v$ \\
\hline$S_{p}$ & $\begin{array}{l}\text { pressure side curvilinear distance from the } \\
\text { front stagnation line of the test blade }\end{array}$ \\
\hline
\end{tabular}


$S_{p f} \quad$ full length of pressure side curvilinear distance from the front stagnation line to the trailing edge, $=188 \mathrm{~mm}$

$S_{s} \quad$ suction side curvilinear distance from the front stagnation line of the test blade

$S_{s f}$ full length of suction side curvilinear distance from the front stagnation line to he trailing edge, $=154 \mathrm{~mm}$

$S h$ local Sherwood number, as determined from Eq. (2)

\section{Injection Hole Rows}

$S L$

$S P$

SS

\section{Greek Symbols}

$\Delta t$

$v$

$\rho_{\mathrm{s}}$

$\rho_{\nu, w}$

$\rho_{2}$

$\rho_{x}$ row of injection holes that are located on the row of injection holes that are located on the pressure side of test blade row of injection holes that are located on the suction side of test blade

total time for the test blade being exposed in the air-stream

kinematic viscosity of air

density of solid naphthalene

local naphthalene vapor density on the test blade surface

air density of the secondary flows

air density of the approaching mainstream front stagnation line

\section{References}

Abhari, R. S., and Epstein, A. H., 1994. An Experimental Study of Film Cooling in a Rotating Transonic Turbine, Journal of Turbomachinery, Vol. 116, pp. 63-70.

Camci. C., and Arts, T., 1985. Experimental Heat Transfer Investigation Around the Film-Cooled Leading Edge of a High-Pressure Gas Turbine Rotor Blade, Journal of Engineering for Gas Turbines and Power, Vol. 107, pp. 1016-1021.

Camci, C., and Arts, T., 1990. An Experimental Convective Heat Transfer Investigation Around a Film-Cooled Gas Turbine Blade, Journal of Turbomachinery, Vol. 112, pp. 497-503.

Chen, P. H., and Goldstein, R. J., 1992. Convective Transport Phenomena on the Suction Surface of a Turbine Blade Including the Influence of Secondary Flows Near the Endwall, Journal of Turbomachinery, Vol. 114, pp. 776-787.

Chen, P. H., Miao, J. M., and Chen, J. W., 1994a. Convective Transport Phenomena for Stagnation Film Cooling, ASME HTD-Vol. 300, pp. 31-44.

Chen, P. H., Chen, J. J., Miao, J. M., Chou, S. F., and Liu, M., 1994 b. The Effect of Upstream Conditions on the Convective Transport Phenomena Over a Turbine Blade, ASME HTD-Vol. 300, pp. 63-81.

Cho, H. H., Jabbari, M. Y., and Goldstein, R. J., 1994. Mass Transfer With Flow Through an Array of Rectangular Cylinders, Journal of Heat Transfer, Vol. 116, pp. 904-911.

Demuren, A. O., Rodi, W., and Schonung, B., 1986. Systematic Study of Film Cooling With a Three-Dimensional Calculation Procedure, Journal of Turbomachinery, Vol. 108, pp. 124-130.

Dring, R. P., Blair, M. F., and Joslyn, H. D., 1980. An Experimental Investigation of Film Cooling on a Turbine Rotor Blade, Journal of Engineering for Gas Turbines and Power, Vol. 102, pp. 81-87.

Goldstein, R. J., and Taylor, J. R., 1982. Mass Transfer in the Neighborhood of Jets Entering a Crossflow, ASME Paper No. 82-HT-62.

Honami, S., Shizawa, T., and Uchiyama, A., 1994. Behavior of the Laterally Injected Jet in Film Cooling: Measurements of Surface Temperature and Velocity/Temperature Field Within the Jet, Journal of Turbomachinery, Vol. 116, pp. 106-112.

Ito, S., Goldstein, R. J., and Eckert, E. R. G., 1978. Film Cooling of a Gas Turbine Blade, Journal of Engineering for Gas Turbines and Power, Vol. 100, pp. 476-481

Jubran, B., and Brown, A., 1985. Film Cooling From Two Rows of Holes Inclined in the Streamwise and Spanwise Directions, Journal of Engineering for Gas Turbines and Power, Vol. 107, pp. 84-91.

Karni, J., and Goldstein, R. J., 1990. Surface Injection Effect on Mass Transfer From a Cylinder in Crossflow: A Simulation of Film Cooling in the Leading Edge Region of a Turbine Blade, Journal of Turbomachinery, Vol. 112, pp. 418-427.

Kline, S. J., and McClintock, F. A., 1953. Describing Uncertainties in Single Sample Experiments, Journal Mechanical Engineering, Vol. 75 , pp. 3-8.

Kurse, H., 1985. Effects of Hole Geometry, Wall Curvature and Pressure Gradient on Film Cooling Downstream of a Single Row, Heat Transfer and Cooling in Gas Turbines, AGARD-CP-390.

Mayle, R. E., 1991. The Role of Laminar-Turbulent Transition in Gas Turbine Engines, Journal of Turbomachinery, Vol. 113, pp. 507-539. Mehendale, A. B., Han, J. C., and Ou, S., 1991. Influence of High Mainstream Turbulence on Leading Edge Heat Transfer, Journal of Heat Transfer, Vol. 113, pp. 843-850.

Mehendale, A. B., and Han, J. C., 1992. Influence of High Mainstream Turbulence on Leading Edge Film Cooling Heat Transfer, Journal of Turbomachinery, Vol. 114, pp. 707-714.

Mehendale, A. B., Han, J.-C., Ou, S., and Lee, C. P., 1994. Unsteady Wake over a Linear Turbine Blade Cascade With Air and $\mathrm{CO}_{2}$ Film Injection: Part II- Effect on Film Effectiveness and Heat Transfer Distributions, Journal of Turbomachinery, Vol. 116, pp. 730-737.

Mick, W. J., and Mayle, R. E., 1988. Stagnation Film Cooling and Heat Transfer Including Its Effect Without the Hole Pattern, Journal of Turbomachinery, Vol. 110, pp. 66-72.

Nirmalan, N. V., and Hylton, L. D., 1990. An Experimental Study of Turbine Vane Heat Transfer With Leading Edge and Downstream Film Cooling, Journal of Turbomachinery, Vol. 112, pp. 477-487.

Ou, S., Mehendale, A. B., and Han, J. C., 1992. Influence of High Mainstream Turbulence on Leading Edge Film Cooling Heat Transfer: Effect of Film Hole Row Location, Journal of Turbomachinery, Vol. 114, pp. 716-723. 
Ou, S., and Han, J. C., 1992. Influence of Mainstream Turbulence on Leading Edge Film Cooling Heat Transfer Through Two Rows of Inclined Slots, Journal of Turbomachinery, Vol. 114, pp. 724-733.

Ou, S., and Han, J. C., 1994a. Leading Edge Film Cooling Heat Transfer Through One Row of Inclined Film Slots and Holes Including Mainstream Turbulence Effects, Journal of Heat Transfer, Vol. 116, pp. 561-569.

Ou, S., and Han, J. C., 1994b. Unsteady Wake Effect on Film Effectiveness and Heat Transfer Coefficient From a Turbine Blade With One Row of Air and $\mathrm{CO}_{2}$ Film Ejection, Journal of Heat Transfer, Vol. 116, pp. 921-928.

Sakata, K., and Kumagai, T., 1983. Experimental Study of Temperature
Effect on Turbine Vane Cooling Performance With Multi-Row Ejection, 1983 Tokyo International Gas Turbine Congress, Paper No. 83-Tokyo-IGTC-17.

Takeishi, K., Aoki, S., Sato, T., and Tsukagoshi, K., 1992. Film Cooling on a Gas Turbine Rotor Blade, Journal of Turbomachinery, Vol. 114, pp. 828-834.

Taylor, J. R., 1980. Heat Transfer Phenomena in Gas Turbines, ASME Paper No. 80-GT-172.

Tillman, E. S., Hartel, E. O., and Jen, H. F., 1985. The Prediction of Flow Through Leading Edge Holes in a Film Cooled Airfoil With and Without Inserts, Journal of Engineering for Gas Turbines and Power, Vol. 107, pp. 92-98. 

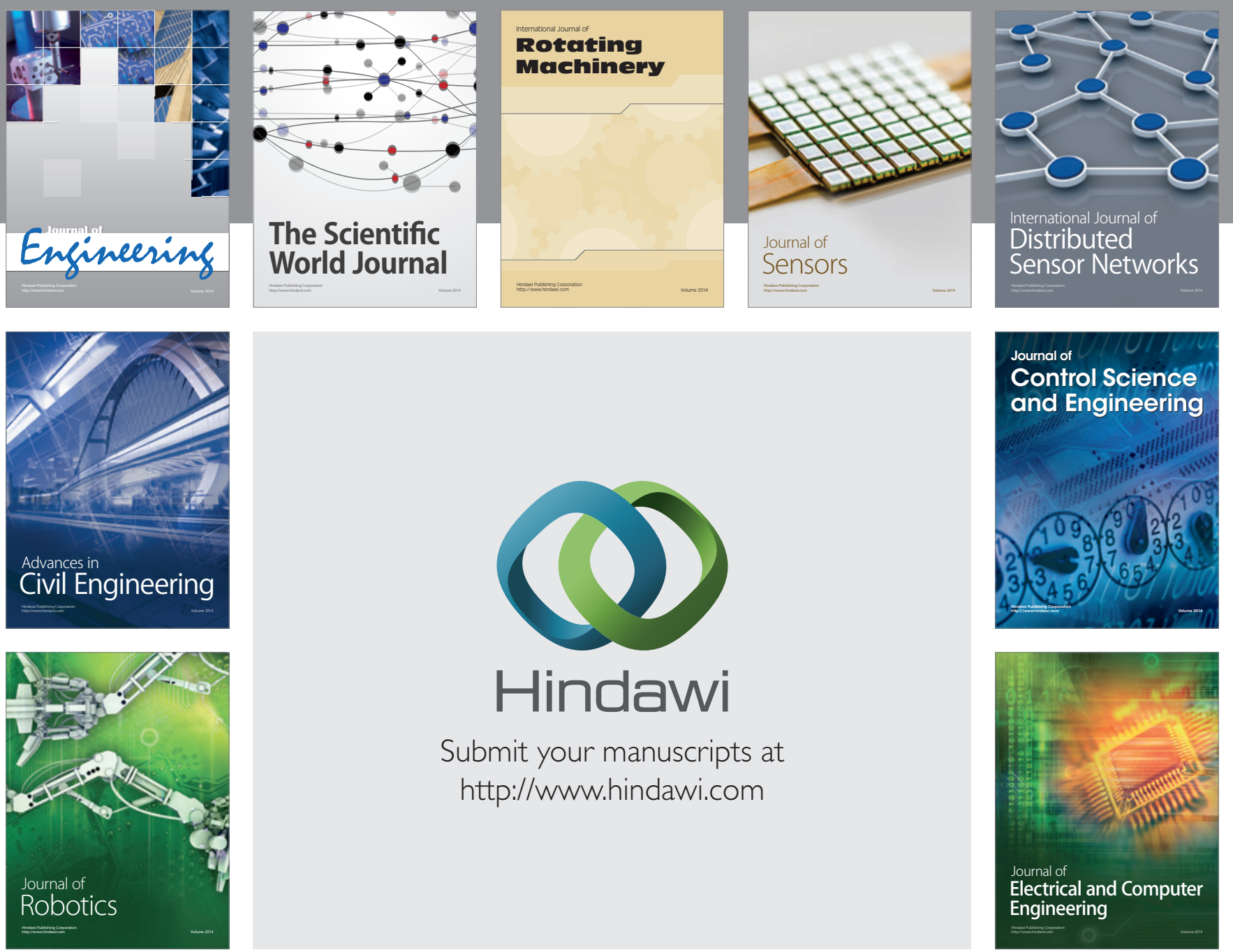

Submit your manuscripts at

http://www.hindawi.com
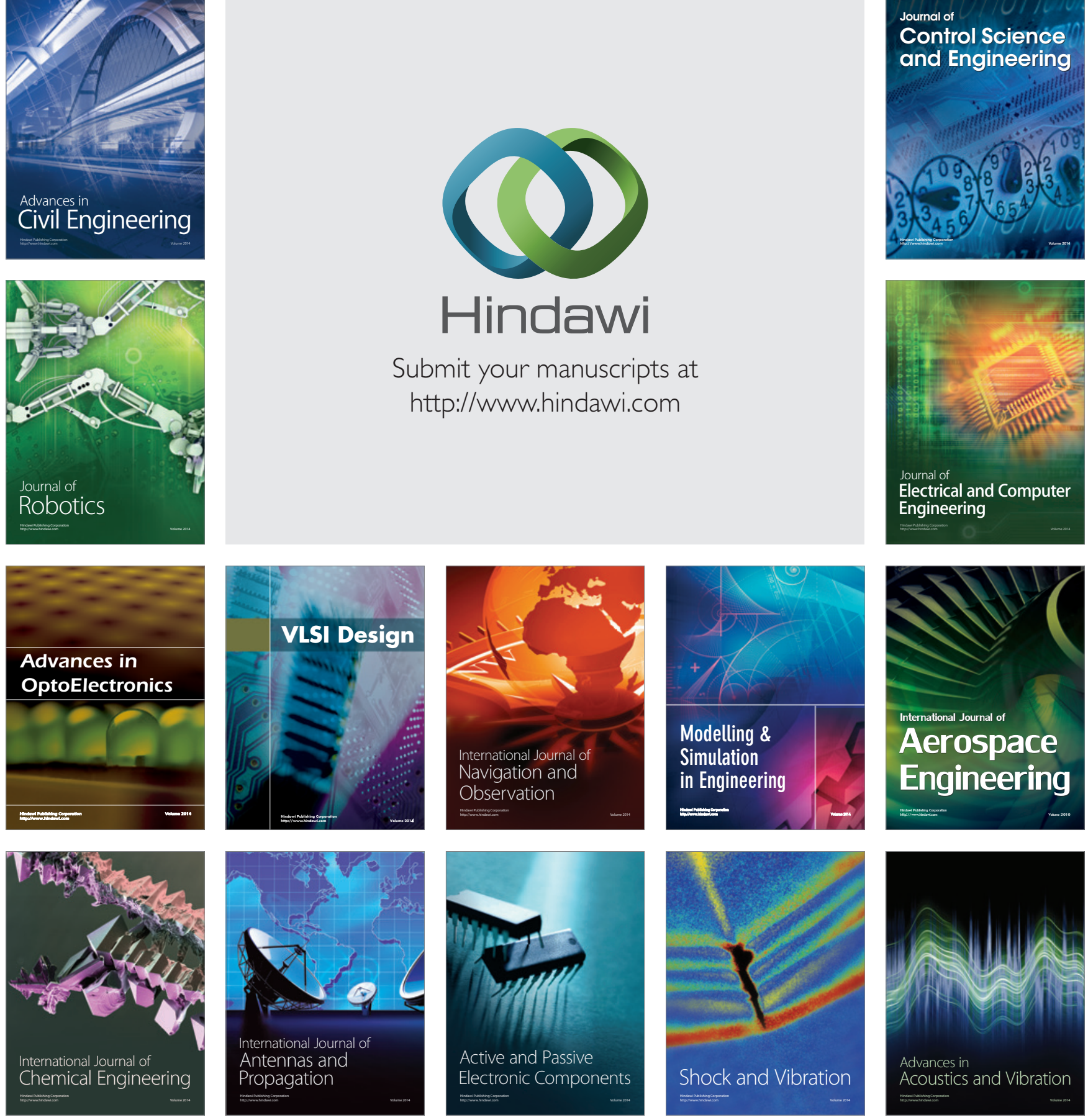